\title{
HIV-1 promoter is gradually silenced when integrated into BACH2 in Jurkat T-cells
}

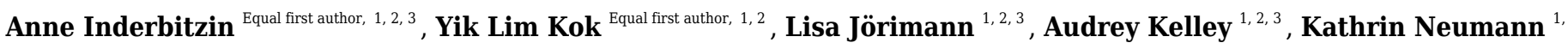 \\ ${ }^{2}$, Daniel Heinzer ${ }^{4,5}$, Toni Cathomen ${ }^{6,7}$, Karin J Metzner ${ }^{\text {Corresp. } 1,2}$ \\ 1 Department of Infectious Diseases and Hospital Epidemiology, Division of Infectious Diseases and Hospital Epidemiology, University Hospital Zurich, \\ Zurich, Zurich, Schweiz \\ 2 Institute of Medical Virology, University of Zurich, Zurich, Zurich, Schweiz \\ 3 Life Science Zurich Graduate School, University of Zurich, Zurich, Zurich, Schweiz \\ 4 Institute for Neuropathology, University Hospital Zurich, Zurich, Zurich, Schweiz \\ 5 Neuroscience Center Zurich Graduate School, University of Zurich, Zurich, Zurich, Schweiz \\ 6 Institute for Transfusion Medicine and Gene Therapy, Medical Center - University of Freiburg, Freiburg, Germany \\ 7 Faculty of Medicine, University of Freiburg, Freiburg, Germany \\ Corresponding Author: Karin J Metzner \\ Email address: Karin.Metzner@usz.ch
}

Background. The persistence of the latent HIV-1 reservoir is a major obstacle to cure HIV-1 infection. HIV-1 integrates into the cellular genome and some targeted genomic loci are frequently detected in clonally expanded latently HIV-1 infected cells, for instance, the gene BTB domain and CNC homology 2 (BACH2).

Methods. We investigated HIV-1 promoter activity after integration into specific sites in $B A C H 2$ in Jurkat T-cells. The HIV-1-based vector LTatCL[M] contains two fluorophores: 1.) Cerulean, which reports the activity of the HIV-1 promoter, and 2.) mCherry driven by a constitutive promotor and flanked by genetic insulators. This vector was inserted into introns 2 and 5 of BACH2 of Jurkat T-cells via CRISPR/Cas 9 technology in the same and convergent transcriptional orientation of $B A C H 2$, and into the genomic safe harbour AAVS1. Single cell clones representing active (Cerulean ${ }^{+} / \mathrm{mCherry}^{+}$) and inactive (Cerulean ${ }^{-}$Cherry $^{+}$) HIV-1 promoters were characterized.

Results. Upon targeted integration of the $5.3 \mathrm{~kb}$ vector LTatCL[M] into $B A C H 2$, the HIV-1 promoter was gradually silenced as reflected by the decrease in Cerulean expression over a period of 162 days. Silenced HIV-1 promoters could be reactivated by TNF- $\alpha$ and Romidepsin. This observation was independent of the targeted intron and the transcriptional orientation. BACH2 mRNA and protein expression was not impaired by mono-allelic integration of LTatCL[M].

Conclusion. Successful targeted integration of the HIV-1-based vector LTatCL[M] allows longitudinal analyses of HIV-1 promoter activity. 


\section{HIV-1 promoter is gradually silenced when integrated 2 into $B A C H 2$ in Jurkat T-cells}

3

4

5

6

7 8

$9 \quad{ }^{2}$ Institute of Medical Virology, University of Zurich, Zurich, Switzerland.

$10{ }^{3}$ Life Science Zurich Graduate School, University of Zurich, Zurich, Switzerland.

$11{ }^{4}$ Institute for Neuropathology, University Hospital Zurich, Zurich, Switzerland.

$12{ }^{5}$ Neuroscience Center Zurich Graduate School, University of Zurich, Zurich, Switzerland.

$13{ }^{6}$ Institute for Transfusion Medicine and Gene Therapy, Medical Center - University of Freiburg,

14 Freiburg, Germany.

15

16

17

18

19

20

21

22

23

Anne Inderbitzin ${ }^{1,2,3}$, Yik Lim Kok ${ }^{1,2}$, Lisa Jörimann ${ }^{1,2,3}$, Audrey Kelley ${ }^{1,2,3}$, Kathrin Neumann ${ }^{1,2}$, Daniel Heinzer ${ }^{4,5}$, Toni Cathomen ${ }^{6,7}$, Karin J. Metzner ${ }^{1,2, *}$

${ }^{1}$ Division of Infectious Diseases and Hospital Epidemiology, University Hospital Zurich, Zurich, ${ }^{7}$ Faculty of Medicine, University of Freiburg, Freiburg, Germany.

AI and YLK contributed equally to this work.

*Corresponding author:

Karin J. Metzner, M.D.

Rämistrasse 100, Zurich, CH-8091/Zurich, Switzerland

Email address: Karin.Metzner@usz.ch 


\section{Abstract}

25 Background. The persistence of the latent HIV-1 reservoir is a major obstacle to cure HIV-1

26 infection. HIV-1 integrates into the cellular genome and some targeted genomic loci are

27 frequently detected in clonally expanded latently HIV-1 infected cells, for instance, the gene

28 BTB domain and $C N C$ homology 2 (BACH2).

29 Methods. We investigated HIV-1 promoter activity after integration into specific sites in $B A C H 2$

30 in Jurkat T-cells. The HIV-1-based vector LTatCL[M] contains two fluorophores: 1.) Cerulean,

31 which reports the activity of the HIV-1 promoter, and 2.) mCherry driven by a constitutive

32 promotor and flanked by genetic insulators. This vector was inserted into introns 2 and 5 of

$33 B A C H 2$ of Jurkat T-cells via CRISPR/Cas9 technology in the same and convergent

34 transcriptional orientation of $B A C H 2$, and into the genomic safe harbour AAVS1. Single cell

35 clones representing active $\left(\right.$ Cerulean $\left.^{+} / \mathrm{mCherry}^{+}\right)$and inactive $\left(\right.$Cerulean $\left.{ }^{-} / \mathrm{mCherry}^{+}\right) \mathrm{HIV}-1$

36 promoters were characterized.

37 Results. Upon targeted integration of the $5.3 \mathrm{~kb}$ vector LTatCL[M] into $B A C H 2$, the HIV-1

38 promoter was gradually silenced as reflected by the decrease in Cerulean expression over a

39

40

41

42

43

44

45

46

47

48

49

50

51

52

53

54

55

56

57

58

59

60

61

62

63

64

65 period of 162 days. Silenced HIV-1 promoters could be reactivated by TNF- $\alpha$ and Romidepsin. This observation was independent of the targeted intron and the transcriptional orientation. $\mathrm{BACH} 2 \mathrm{mRNA}$ and protein expression was not impaired by mono-allelic integration of LTatCL[M].

Conclusion. Successful targeted integration of the HIV-1-based vector LTatCL[M] allows longitudinal analyses of HIV-1 promoter activity.

\section{Keywords}

HIV-1 integration; recurrent integration gene (RIG); HIV-1 persistence; HIV-1-based, dualfluorphore vector; $B A C H 2$; CRISPR/Cas9; genomic safe harbour AAVS1

\section{Introduction}

Antiretroviral therapy (ART) blocks efficiently virus replication, however, does not cure HIV-1 infection due to the presence of replication-competent but silenced proviruses preferentially integrated in long-lived resting CD4 ${ }^{+}$T-cells (Finzi et al. 1997; Wong et al. 1997). Various factors and molecular mechanisms that result in HIV-1 latency have been proposed (Ruelas \& Greene 2013). One such factor might be the integration site of the provirus, which has been suggested to not only be responsible for silencing the provirus, but also supporting cell expansion, thus maintaining the size of the HIV-1 latent reservoir (Maldarelli et al. 2014; Wagner et al. 2014). Integration of HIV-1 into the human genome is not random. In vivo and ex vivo HIV-1 integration site analyses revealed that HIV-1 favours integration into introns of active transcription units in gene-dense regions, although a minority of integration events outside of these regions have consistently been observed (Ciuffi \& Bushman 2006; Kok et al. 2016; Mitchell et al. 2004; Schroder et al. 2002; Stevens \& Griffith 1996). Furthermore, HIV-1 appears to target active transcription units that are in close proximity to the nuclear pore (Marini et al. 2015). On the population level, intragenic HIV-1 does not have a preference for either transcriptional orientation of the targeted gene (Cohn et al. 2015; Schroder et al. 2002; Stevens \& Griffith 1996). HIV-1-infected cells can undergo clonal expansion and increase over time (Cesana et al. 2017; Cohn et al. 2015; Maldarelli et al. 2014; Rezaei \& Cameron 2015; Satou et 
66 al. 2017; Wagner et al. 2014), and the proviruses in these clonally expanded cells are often

67 located in specific regions of the human genome. One recurrent integration gene (RIG) that has

68 been observed across patients'cells in numerous independent studies is the gene $B A C H 2$, in

69 which the provirus is almost exclusively found in intron 5 and in the same transcriptional

70 orientation as $B A C H 2$ (Cesana et al. 2017; Ikeda et al. 2007; Imamichi et al. 2014; Mack et al.

71 2003; Maldarelli et al. 2014; Wagner et al. 2014). Since these $B A C H 2$ integration sites were

72 identified in HIV-1-infected individuals who have been on ART for several years, it is

73 conceivable that these proviruses are inactive, although it remains unknown whether this

74 presumed inactivity is a result of integration site-dependent silencing of replication-competent

75 proviruses or due to defective proviruses.

76 To address the question of whether the HIV-1 promoter would be silenced upon integration into

77 intron 5 of $B A C H 2$ in the same transcription orientation, we employed a modified version of our

78 dual-fluorophore HIV-1-based vector, LTatC[M], which reproduces features of active and latent

79 HIV-1 infections (Kok et al. 2018). This vector comprises two fluorescent reporter genes: 1.)

80 Cerulean, which reports the activity of the HIV-1 promoter, and 2.) mCherry, the expression of

81 which is driven by a constitutive promoter and further protected from position-effect variegation

82 by a pair of flanking genetic insulators to identify cells harbouring an integrated vector (Uchida

83 et al. 2013; Villemure et al. 2001; Yahata et al. 2007). In this study, we investigate whether

84 CRISPR/Cas9-mediated targeted HIV-1 integration in $B A C H 2$ is feasible and would lead to

85 inactivation of the HIV-1 promoter over time, and if so, whether it is locus and/or transcriptional

86 orientation dependent.

\section{Material and Methods}

88

89

90

91

92

93

94

95

96

97

98

99

100

101

102

103

104

105

106

107

108
Generation of LTatCL[M] with target locus homologous arms and Cas9/guide RNA-encoding plasmids

In LTatC $[\mathrm{M}]$ the 3 'LTR is located downstream of the second fluorophore mCherry to enable retrovirus production and subsequent infection of target cells (Kok et al. 2018). LTatC[M] was modified to LTatCL[M], i.e., the 3'LTR (L) was inserted between Cerulean (C) and the insulator cHS4 (Figure 1A) to further enhance the transcriptional independence of the HIV-1 promoter controlled Cerulean. For targeted integration of our HIV-1-based, dual-fluorophore vector, retrovirus production is not required. Thus, the HIV-1 3'LTR was relocated immediately downstream of Cerulean. Additionally, a polyA signal was inserted between mCherry ([M]) and the second insulator sMAR8 (Figure 1A). The homologous regions on both sides of the targeted HIV-1 integration site in the human genome, were obtained from NCBI GenBank: $B A C H 2$ intron 5 (Accession No: NT_007299.13; 5' arm nucleotides 93'502-94'355, 3' arm nucleotides 94'35695'206), BACH2 intron 2 (5' arm nucleotides 339'363-340'186, 3' arm nucleotides 340'187341'034), and AAVS1 (Accession No: NC_000019.10; 5' arm nucleotides 1'399-2'218, 3' arm nucleotides 2'219-3'051). Targeted integration sites are depicted in Figure 1B. Primers to amplify the respective target locus homologous arms are listed in Supplementary Table 1. Each PCR reaction contained 100 ng of human genomic DNA (Sup-T1 cell line; obtained through the NIH AIDS Reagent Program, Division of AIDS, NIAID, NIH, from Dr. Dharam Ablashi), 1x Platinum Taq PCR buffer (ThermoFisher), $2 \mathrm{mM} \mathrm{MgCl}$ (ThermoFisher), $0.2 \mathrm{mM}$ dNTP (NEB), $0.4 \mu \mathrm{M}$ of each forward and reverse primer, and $1 \mathrm{U}$ Platinum Taq polymerase (ThermoFisher) in a total volume of $50 \mu \mathrm{L}$. The PCR cycling conditions were as

Peer] reviewing PDF | (2020:08:51698:1:1:NEW 13 Oct 2020) 
109 follows: $94^{\circ} \mathrm{C}$ for $2 \mathrm{~min} ; 35$ cycles of $\left(94^{\circ} \mathrm{C}\right.$ for $30 \mathrm{~s}, 55^{\circ} \mathrm{C}$ for $30 \mathrm{~s}, 68^{\circ} \mathrm{C}$ for $\left.1 \mathrm{~min}\right) ; 68^{\circ} \mathrm{C}$ for 5 $110 \mathrm{~min} ; 4^{\circ} \mathrm{C}$ hold.

111 The respective pair of target locus homologous arms were cloned into pGEM-T Easy vector

112 (Promega). Subsequently, the dual-fluorophore vector LTatCL[M] was cloned into each plasmid

113 in the same or convergent orientation via blunt-end cloning. The 6 plasmids $\mathrm{p} B A C H 2$ i5-,

$114 \mathrm{pBACH} 2$ i2-, and pAAVS1-LTatCL[M] were generated, containing the homologous arms of the

115 targeted HIV-1 integration loci in $B A C H 2$ intron 5, $B A C H 2$ intron 2, and in the safe harbour loci

116 AAVS1, respectively, containing LTatCL[M] in both transcriptional orientations (s and c)

117 (Figure 1A).

118 Plasmids encoding Cas9 and guide RNAs were based on pX458 (Addgene plasmid 48138)

119 (Supplementary Table 1). Annealing of $100 \mu \mathrm{M} 5^{\prime}$ phosphorylated primers for the guide RNAs

120 was performed using the following conditions: $80^{\circ} \mathrm{C}$ for $5 \mathrm{~min}, 65^{\circ} \mathrm{C}$ for $7 \mathrm{~min}, 60^{\circ} \mathrm{C}$ for $7 \mathrm{~min}$,

$12155^{\circ} \mathrm{C}$ for $7 \mathrm{~min}, 50^{\circ} \mathrm{C}$ for $7 \mathrm{~min}, 45^{\circ} \mathrm{C}$ for $7 \mathrm{~min}, 40^{\circ} \mathrm{C}$ for $7 \mathrm{~min}, 35^{\circ} \mathrm{C}$ for $7 \mathrm{~min}, 30^{\circ} \mathrm{C}$ for $7 \mathrm{~min}$,

$12225^{\circ} \mathrm{C}$ for $7 \mathrm{~min}$, and $4^{\circ} \mathrm{C}$ hold. The annealed guide RNA primers were separately cloned into

$123 \mathrm{pX} 458$.

124 All plasmid sequences were confirmed by next-generation sequencing. Briefly, plasmids were

125 gel purified, diluted to $0.2 \mathrm{ng} / \mu \mathrm{l}$, and $1 \mathrm{ng}$ of the plasmids were processed using the Illumina

126 Nextera XT DNA library Prep kit. The DNA libraries were subsequently paired-end or single-

127 end sequenced with an Illumina MiSeq using the MiSeq Reagent Kit v3 (150-cycle). Plasmid

128 maps are shown in Figure 1A.

\section{Transfection of Jurkat T-cells and single cell sorting}

130 Prior to transfection, the six LTatCL[M] vectors (pBACH2_i5-, $\mathrm{p} B A C H 2 \_\mathrm{i} 5 \mathrm{c}-, \mathrm{p} B A C H 2$ i2s-, 131 pBACH2_i2c-, pAAVS1_s-, and pAAVS1_c- LTatCL[M]) were linearized using 100 units of

132 NsiI (NEB)/20 $\mu \mathrm{g}$ DNA. For transfection, 1 million Jurkat T-cells were resuspended in $100 \mu \mathrm{L}$

133 Nucleofector solution (Cell Line Nucleofector ${ }^{\mathrm{TM}}$ Kits, Lonza) and combined with $2 \mu \mathrm{g}$ of the

134 linearized dual-fluorophore vector and $2 \mu \mathrm{g}$ of the corresponding gRNA/Cas 9 plasmid:

135 pX458_gBACH2 $2^{94,355-94,356}$ (intron 5), pX458_gBACH2 $2^{340,186-340,187}$ (intron 2), and

136 pX458_gAAVS1 ${ }^{2218-2219}$ (AAVS1). pSpCas9(BB)-2A-GFP (pX458) was a gift from Feng Zhang

137 (Addgene plasmid \# 48138) (Ran et al. 2013). Nucleofection was performed using the program

138 X-001 for Jurkat T-cells (Amaxa ${ }^{\mathrm{TM}}$ Nucleofector ${ }^{\mathrm{TM}}$ II, Lonza). Cells were cultured in RPMI-

1391640 medium media supplemented with 10\% fetal bovine serum (FBS) and 1\% Penicillin

140 Streptomycin (10’000 units/ml Penicillin, $10 \mathrm{mg} / \mathrm{ml}$ Streptomycin).

141 At day 9 post transfection, cells were analysed using fluorescence-activated cell sorting (FACS)

142 and sorted at 20 cells per well in 96-well plates using a BD FACSAria ${ }^{\text {TM }}$ III (BD Biosciences).

143 Two cell phenotypes were sorted: 1 . Cerulean ${ }^{+} / \mathrm{mCherry}^{+}$and 2 . Cerulean $/ \mathrm{mCherry}{ }^{+}$. This was

144 done for each nucleofected cell population: $B A C H 2 \_\mathrm{i} 5 \mathrm{~s}, B A C H 2 \_\mathrm{i} 5 \mathrm{c}, B A C H 2 \_\mathrm{i} 2 \mathrm{~s}, \mathrm{BACH} 2 \_\mathrm{i} 2 \mathrm{c}$,

145 AAVS1_s, and AAVS1_c. After 50 days, expanded cell cultures were analysed by flow

146 cytometry and subsequently single cell sorted. Longitudinal flow cytometric analysis of the cells

147 were done with the LSRFortessa II (BD Biosciences) and data were analysed using the FlowJo

148 Software v.10.0.8. (FLOWJO, LLC) (Figure 1C).

149 Activation of silenced HIV-1 promoter in cells with integrated LTatCL[M] in BACH2

150 Over time silenced HIV-1 promoter in sorted Cerulean ${ }^{+} / \mathrm{mCherry}^{+}$monoclonal cell lines were

151 reactivated using $10 \mathrm{ng} / \mu \mathrm{L}$ Tumor Necrosis Factor Alpha (TNF- $\alpha$ ) and $4 \mathrm{nM}$ Romidepsin (Ro)

152 (Selleckchem). After $24 \mathrm{~h}$ the cells were analysed by flow cytometry. 
153

154

155

156

157

158

159

160

161

162

163

164

165

166

167

168

169

170

171

172

173

174

175

176

177

178

179

180

181

182

183

184

185

186

187

188

189

190

191

192

193

194

195

196

Amplifying the junctions of LTatCL[M] integration into BACH2 and AAVS1

Genomic DNA was extracted from 5 million transfected Jurkat T-cells using the DNeasy Blood and Tissue kit (Qiagen) and quantified by Quant-iT ${ }^{\mathrm{TM}}$ PicoGreen $^{\mathrm{TM}}$ dsDNA Assay kit (ThermoFisher Scientific). To verify the targeted integration of the dual-fluorophore vector LTatCL[M] into $B A C H 2$ or AAVS1, the junctions of targeted integration were amplified by (semi-)nested PCR using $300 \mathrm{ng}$ genomic DNA containing 1x PCR buffer (Sigma Aldrich), 1.5 $\mathrm{mM} \mathrm{MgCl} 2,0.2 \mathrm{mM}$ dNTPs, $0.5 \mu \mathrm{M}$ of each respective forward and reverse primer

(Supplementary Table 1), and 0.5 U JumpStart Taq DNA polymerase (Sigma-Aldrich) in a total volume of $25 \mu \mathrm{L}$. The PCR cycling conditions were as follows: $94^{\circ} \mathrm{C}$ for $2 \mathrm{~min} ; 35-40$ cycles of $\left(94^{\circ} \mathrm{C}\right.$ for $30 \mathrm{~s}, 63^{\circ} \mathrm{C}$ for $30 \mathrm{~s}, 72^{\circ} \mathrm{C}$ for $\left.2 \mathrm{~min}\right) ; 72^{\circ} \mathrm{C}$ for $5 \mathrm{~min} ; 4^{\circ} \mathrm{C}$ hold.

Mono-allelic or bi-allelic integration of LTatCL[M] into $B A C H 2$ and AAVS1 was verified by PCR containing $100 \mathrm{ng}$ genomic DNA, 1x PCR buffer, $1.5 \mathrm{mM} \mathrm{MgCl}_{2}, 0.2 \mathrm{mM}$ dNTPs, $0.5 \mu \mathrm{M}$ of each respective forward and reverse primers (Supplementary Table 1), and $0.5 \mathrm{U}$ JumpStart Taq DNA polymerase in a total volume of $25 \mu \mathrm{L}$. The PCR cycling conditions were as follows: $94^{\circ} \mathrm{C}$ for $2 \mathrm{~min} ; 35$ cycles $\left(94^{\circ} \mathrm{C}\right.$ for $30 \mathrm{~s}, 63^{\circ} \mathrm{C}$ for $30 \mathrm{~s}, 72^{\circ} \mathrm{C}$ for $\left.2 \mathrm{~min}\right) ; 72^{\circ} \mathrm{C}$ for $5 \mathrm{~min} ; 4^{\circ} \mathrm{C}$ hold.

Amplicons were sequenced by Sanger sequencing. The sequencing reaction contains 1x Seqmix (Big Dy Termination v1.1, 1x Dilution Buffer (ThermoFisher)), and 100 ng DNA in a total volume of $40 \mu \mathrm{L}$. $0.2 \mu \mathrm{M}$ primer was added (Supplementary Table 1). The PCR cycling condition were as follows: 40 cycles $\left(96^{\circ} \mathrm{C}\right.$ for $30 \mathrm{~s}, 50^{\circ} \mathrm{C}$ for $30 \mathrm{~s}, 60^{\circ} \mathrm{C}$ for $\left.4 \mathrm{~min}\right) ; 4^{\circ} \mathrm{C}$ hold. Sequencing was performed following the manufacturer's instruction on an 3130xl Genetic Analyzer (Applied Biosystems).

\section{Near full-length amplification of integrated vector LTatCL[M]}

Genomic DNA was extracted from 3 million transfected cells using the DNeasy Blood and Tissue kit and quantified by Quant-iT ${ }^{\mathrm{TM}}$ PicoGreen ${ }^{\mathrm{TM}}$ dsDNA Assay kit. To investigate the integrity of the integrated vector LTatCL[M], near full-length amplification of the vector was performed, using genomic 300 ng DNA, 1x Long Amp Taq Reaction Buffer (NEB), $0.4 \mathrm{mM}$ dNTPs, $0.5 \mu \mathrm{M}$ of each forward and reverse primer (Supplementary Table 1) and 2.5 U Long Amp Taq Polymerase (NEB) in a total volume of $25 \mu \mathrm{L}$. The PCR cycling conditions were as follows: $94^{\circ} \mathrm{C}$ for $30 \mathrm{~min} ; 30$ cycles of $\left(94^{\circ} \mathrm{C}\right.$ for $20 \mathrm{~s}, 58-61^{\circ} \mathrm{C}$ for $30 \mathrm{~s}, 72^{\circ} \mathrm{C}$ for $\left.5 \mathrm{~min}\right) ; 72^{\circ} \mathrm{C}$ for $10 \mathrm{~min} ; 4^{\circ} \mathrm{C}$ hold. $1 \mathrm{ng}$ purified amplicons were processed with the Nextera XT DNA Library Preparation Kit (Illumina) and subsequently sequenced using the MiSeq reagent Kit v2 as described above.

\section{Quantification of BACH2 mRNA expression}

RNA was extracted from 3 million transfected cells using the All Prep DNA/RNA kit (Qiagen) and quantified by Nanodrop 1000. 800ng RNA was reverse transcribed with Prime Script Reverse Transcriptase (Takara) according to manufacturer's instructions. To exclude contamination of plasmid and genomic DNA contamination, reactions lacking reverse transcriptase were included for each RNA sample. To quantify the mRNA level of $B A C H 2$, qPCR reactions were performed in triplicates for each sample. cDNA was diluted 1:10 mixed with 1x PCR buffer (Sigma Aldrich), $1.5 \mathrm{mM} \mathrm{MgCl}_{2}, 0.2 \mu \mathrm{M}$ dNTP (NEB), $0.5 \mu \mathrm{M}$ of each Fw and Rv primers, 1x SYBR ${ }^{\circledR}$ Green, $50 \mathrm{nM}$ Rox, 0.5 U JumpStart Taq Polymerase (SigmaAldrich) in a total volume of $25 \mu$. For each reaction, primer pair was chosen to amplify a specific region of the $B A C H 2$ mRNA, spanning exon 7-8. As a mRNA expression control

PeerJ reviewing PDF | (2020:08:51698:1:1:NEW 13 Oct 2020) 
197 glycerinaldehyd-3-phosphat-dehydrogenase (GAPDH) was amplified with GAPDH-specific

198 primers (Supplementary Table 1). The qPCR cycling conditions were as follows: $94^{\circ} \mathrm{C}$ for $2 \mathrm{~min}$; 19940 cycles $\left(94^{\circ} \mathrm{C}\right.$ for $30 \mathrm{~s}, 55^{\circ} \mathrm{C}$ for $30 \mathrm{~s}, 63^{\circ} \mathrm{C}$ for $1 \mathrm{~min}$ (collect data)); $72^{\circ} \mathrm{C}$ for $2 \mathrm{~min}$; $95^{\circ} \mathrm{C}$ for $20015 \mathrm{~s} ; 4^{\circ} \mathrm{C}$ hold. Melt curves were collected to analyze specificity of the amplification. The qPCR 201 was performed in the ABI 7800 real-time PCR thermos-cycler then analysed using the 7500 202 Software v2.0.4, using the comparative $C_{t}$ method(Livak \& Schmittgen 2001).

203 Quantification of BACH2 protein expression

204 Cells were lysed using assay lysis buffer (50 mM Tris-HCL pH8, $150 \mathrm{mM} \mathrm{NaCl}, 0.5 \% \mathrm{Na}$ 205 deoxycholate, $0.5 \%$ Triton $\mathrm{X}-100,1 \mathrm{x}$ Protease inhibitor, $\mathrm{ddH}_{2} \mathrm{O}$ ) and protein was quantified 206 using the Bicinchoninic acid assay (BCA) (Pierce ${ }^{\mathrm{TM}} \mathrm{BCA}$ Protein Assay Kit). $40 \mu \mathrm{g}$ protein were 207 mixed with loading dye and loaded on a Bolt ${ }^{\mathrm{TM}} 4-12 \%$ Bis-Tris Plus Gels (ThermoFisher Scientific). Subsequently, proteins were transferred onto a nitrocellulose membrane (iBlot ${ }^{\mathrm{TM}} 2$ Transfer Stacks, ThermoFisher Scientific) blocked for $1 \mathrm{~h}$ at RT with 5\% Top-Block wt/vol in PBS supplemented with Tween-20 (10x PBS pH7.4, 0.1\% Tween 20, and $\mathrm{ddH}_{2} \mathrm{O}$ ). For protein detection, the membrane was incubated with primary antibody (1/400 diluted rabbit anti-BACH2 antibody (PA5-23642, ThermoFisher Scientific) and 1/5'000 diluted rabbit-anti-GAPDH antibody (ab9485, Abcam)) overnight at $4^{\circ} \mathrm{C}$. After washing the membrane four times with $1 \mathrm{x}$ PBS-T, the secondary antibody, 1/10'000 diluted goat anti-rabbit IgG H\&L (HRP) (ab97051, Abcam) was added and the membrane was incubated at RT for $1 \mathrm{~h}$. The membrane was then washed four times with 1x PB-T. To visualize the protein, Immobilon Crescendo Western HRP substrate (Merck) was added to the membrane. Chemiluminescence was captured with the Stella system (model 3200, Matlab Group Companies).

\section{Results}

Targeted integration of the $5.3 \mathrm{~kb} H I V$-1-based, dual-fluorophore vector LTatCL[M] into BACH2 and AAVS1 via CRISPR/Cas9-mediated homology directed repair

To investigate specific effects of HIV-1 integration into $B A C H 2$, four constructs were generated containing the vector LTatCL[M] flanked by $B A C H 2$ homologous arms (Figure 1A) and integrated in Jurkat T-cells by means of the CRISPR/Cas9 technology. The constructs were integrated into intron 5 of $B A C H 2$ in 1.) the in vivo observed same (s) and 2.) the convergent (c) transcriptional orientation as $B A C H 2$ to investigate the potential impact of transcriptional orientation on HIV-1 promoter activity. Furthermore, LTatCL[M] was integrated into intron 2 of $B A C H 2$ in 3.) the same and 4.) the convergent transcriptional orientation to investigate the position effect of HIV-1 integration into $B A C H 2$. Intron 2 was chosen as it has not yet been observed in HIV-1 infected patients, however, it was frequently observed as HIV-1 integration locus in human $\mathrm{CD} 34^{+}$hematopoietic stem cells infected in vitro with HIV-1(Maldarelli et al. 2014). In addition, LTatCL[M] was integrated into intron 1 of PPP1R $12 C$ (protein phosphatase 1 regulatory subunit $12 \mathrm{C}$ ) in again both transcriptional orientations. This genomic locus was previously identified as preferred site for integration of adeno-associated virus (AAV) DNA and designated AAVS1 (AAV integration site)(Kotin et al. 1992). AAVS1 is widely used as genomic safe harbour (GSH) althought not without some limitations particularly in the context of future use in gene therapy trials(Papapetrou \& Schambach 2016; Sadelain et al. 2011). Nevertheless, for research purposes it is considered a GSH and we expect that the HIV-1 promoter will not be silenced when integrated in this GSH. These six vector constructs and subsequently generated 
240 Jurkat T-cell clones were named $B A C H 2 \_\mathrm{i} 5 \mathrm{~s}, B A C H 2 \_\mathrm{i} 5 \mathrm{c}, B A C H 2 \_\mathrm{i} 2 \mathrm{~s}, B A C H 2$ i2c, AAVS1_c, 241 and AAVS1_s (Figure 1A and B).

242 Jurkat T-cells were nucleofected with linearized plasmids of the six LTatCL[M] constructs. Nine 243 days post transfection, the frequencies of stably transfected Cerulean ${ }^{+} / \mathrm{mCherry}^{+}$and single

$244 \mathrm{mCherry}^{+}$cells were between 0.1 and $1.8 \%$ (Figure 1C). Cells were sorted to enrich

245 Cerulean $^{+} / \mathrm{mCherry}^{+}$(i.e., active HIV-1 promoter) and single mCherry ${ }^{+}$(i.e., inactive HIV-1

246 promoter) cells (Figure 1D).

247 To obtain monoclonal cell lines, a sequential flow cytometric sorting strategy was employed. For 248 all targeted integration variants, Cerulean ${ }^{+} / \mathrm{mCherry}^{+}$and single mCherry ${ }^{+}$cells were first sorted 249 at 20 cells per well in 96-well plates and expanded in culture up to 50 days post transfection. We 250 analysed by means of flow cytometry a total of 92 cell populations, and selected 29 for further 251 expansion. These cells were single-cell sorted to obtain monoclonal cell lines and expanded in 252 culture for at least 25 days prior to following further characterization. In total, 43 single cells 253 expanded resulting in 43 monoclonal cell lines. For each targeted integration variant $\left(B A C H 2 \_\mathrm{i} 5 \mathrm{~s}, B A C H 2 \_\mathrm{i} 5 \mathrm{c}, B A C H 2 \_\mathrm{i} 2 \mathrm{~s}, B A C H 2 \_\mathrm{i} 2 \mathrm{c}, \mathrm{AAVS} 1 \_\mathrm{s}\right.$, and AAVS1_c), at least one monoclonal cell line for each of the two phenotypes $\left(\right.$ Cerulean $^{+} / \mathrm{mCherry}^{+}$and single $\mathrm{mCherry}^{+}$) were obtained with the exception of AAVS1_c, single $\mathrm{mCherry}^{+}$(Table 1). The monoclonal cell lines were characterized as follows.

First, targeted integration of the HIV-1-based, dual-fluorophore vector LTatCL[M] was verified by amplification of a fragment spanning the targeted gene up- or downstream of the 5' or 3'

260 homologous arms, respectively, and LTatCL[M]. Targeted integration was confirmed in 39/43

261 monoclonal cell lines representing all three genomic loci in both orientations and for both

262

263

264 fluorescence phenotypes, except for AAVS1_c single mCherry ${ }^{+}$( Table 1).

Second, targeted integration of LTatCL[M] in those 39 monoclonal cell lines was verified to be mono-allelic by a PCR strategy that allows sufficient amplification only of the not targeted $B A C H 2$ or AAVS1 allele by using primers up- and downstream of the $B A C H 2$ or AAVS1 homologeous arms (Figure 1A) and short PCR extension times. All monoclonal cell lines contained a not targeted allele of the respective targeted integration site (Table 1). Third, $B A C H 2$ mRNA expression was quantified at 120 days post sorting in 11 Cerulean ${ }^{+} / \mathrm{mCherry}^{+}$monolonal cell lines, representing each targeted integration variant. A decrease of $B A C H 2$ mRNA expression could not be observed in any Cerulean ${ }^{+} / \mathrm{mCherry}^{+}$ monolonal cell line (Figure 2A, Table 1). Forth, the potential impact on $\mathrm{BACH} 2$ protein expression after targeted integration of LTatCL[M] into $B A C H 2$ was investigated by Western blot analyses at 120 days post sorting. In line with unaltered $\mathrm{BACH} 2 \mathrm{mRNA}$ expression, $\mathrm{BACH} 2$ protein expression was not impaired compared to non-transfected Jurkat T-cells in all 35 monoclonal cell lines tested (Figure 2B, Table 1).

Fifth, HIV-1 integration can affect various aspects of cellular physiology, for instance, cell proliferation. To test whether targeted integration of LTatCL[M] into $B A C H 2$ would lead to an evolutionary advantage in cell growth, a cell-growth competition assay was performed. The stably Cerulean and mCherry expressing $B A C H 2$ i5s_ 1.1 Cerulean $^{+} / \mathrm{mCherry}^{+}$and AAVS1_s_2.1 Cerulean ${ }^{+} / \mathrm{mCherry}^{+}$monoclonal cell lines were combined in an approximately 1:1 ratio with the parental Jurkat T-cell line and cocultured for 25 days. A comparable decrease of Cerulean ${ }^{+} / \mathrm{mCherry}^{+}$expression was observed for both the $B A C H 2$ i5s_1.1 Cerulean $^{+} / \mathrm{mCherry}^{+}$and the AAVS1_s_2.1 Cerulean ${ }^{+} / \mathrm{mCherry}^{+}$monoclonal cell line (Supplementary Figure 5). 
286 In summary, we successfully performed targeted integration of the $5.3 \mathrm{~kb}$ HIV-1-based, dual-

287 fluorophore vector LTatCL[M] into various loci of the human genome via CRISPR/Cas9-

288 mediated homology-directed repair. We subsequently generated monoclonal cell lines modelling 289 actively and latently HIV-1-infected cells with integrated LTatCL[M] in either transcriptional

290 orientation in the targeted genomic loci.

291 Silencing of the HIV-1 promoter in Jurkat T-cells with integrated LTatCL[M] in BACH2

292 To study the HIV-1 promoter activity over time in Cerulean ${ }^{+} / \mathrm{mCherry}^{+}$monoclonal cell lines, 293 i.e., active HIV-1 promoter, the fluorescence profile was frequently monitored for 162 days. In 294 the majority of Cerulean ${ }^{+} / \mathrm{mCherry}^{+}$monoclonal cell lines with integrated LTatCL[M] in $295 B A C H 2$, the HIV-1 promoter was gradually silenced as observed by the decline of the frequency of Cerulean ${ }^{+} / \mathrm{mCherry}^{+}$cells to $<50 \%$ in 16/18 monoclonal cell lines within 24-162 days and to $<10 \%$ in 10/18 monoclonal cell lines within 58-162 days (Figure 3A and Supplementary Figure 2). This was observed independent of the $B A C H 2$ introns 2 or 5 chosen for targeted integration of LTatCL[M] and the transcriptional orientation of LTatCL[M] relative to $B A C H 2$. In contrast, in all 5 AAVS1_s and AAVS1_c Cerulean ${ }^{+} / \mathrm{mCherry}^{+}$monoclonal cell lines the frequency of Cerulean ${ }^{+} / \mathrm{mCherry}^{+}$cells remained relatively stable for 162 days ( $>80 \%$ in $4 / 5$ cell clones) as observed for one $\mathrm{BACH} 2$ i5s clone (Figure 3A). Overall, the HIV-1 promoter when integrated into the $\mathrm{BACH} 2$ gene is silenced over time in the majority of Cerulean ${ }^{+} / \mathrm{mCherry}^{+}$monoclonal

304 cell lines whereas it remains active when integrated into AAVS1.

Silenced HIV-1 promoters can be reactivated by TNF- $\alpha$ and Romidepsin

307

308

309

310

311

312

313

314
To evaluate the reactivation of silenced HIV-1 promoters in Cerulean ${ }^{+} / \mathrm{mCherry}^{+}$monoclonal cell lines, which gradually lost Cerulean expression, we performed an activation assay using TNF- $\alpha$ and Romidepsin. TNF- $\alpha$ and Romidepsin in combination have been shown to activate the silenced HIV-1 promoter (Kok et al. 2018; Sogaard et al. 2015). These compounds were used to evaluate the reactivability of the silenced HIV-1 promoter in 8 Cerulean ${ }^{+} / \mathrm{mCherry}^{+}$monoclonal cell lines with integrated LTatCL[M] in $B A C H 2$. After 99 days, $1.6-48.2 \%$ of cells were Cerulean ${ }^{+} / \mathrm{mCherry}^{+}$. Upon treatment with TNF- $\alpha$ and Romidepsin, the frequencies of Cerulean $^{+} / \mathrm{mCherry}^{+}$cells increased to $61.6-89.8 \%$ (Figure $3 \mathrm{~B}$ ), demonstrating that the silenced HIV-1 promoter was reactivatable in those monoclonal cell lines.

\section{Monoclonal single Cherry $^{+}$cell lines harbour large internal deletions in LTatCL[M]}

A total of 17 single mCherry ${ }^{+}$monoclonal cell lines, presumably representing latently HIV-1infected cells, silenced at an early time point upon targeted HIV-1 integration, were treated with TNF- $\alpha$ and Romidepsin to activate the HIV-1 promoter. Cerulean expression was not induced by TNF- $\alpha$ and Romidepsin in any of these 17 monoclonal cell lines (Supplementary Figure 3). To further investigate this, the whole vector LTatCL[M] was amplified and sequenced in 8 of these 17 monoclonal cell lines. Surprisingly, the integrated vector LTatCL[M] in these monoclonal single mCherry $^{+}$cell lines harboured large internal deletions in the 5'HIV-1 LTR, tat, and/or Cerulean cassette (Figure 4). The monoclonal $B A C H 2$ i5s cell lines 3.1 and 3.2, which were derived from the same cell culture after the $1^{\text {st }}$ sort, showed the same deletion in the IRESCerulean region (Figure 4A). A similar observation was made in the monoclonal $B A C H 2$ i2c cell lines 13.1 and 13.3, also derived from the same $1^{\text {st }}$ sorted cell population: The same deletion spanning from the 5'LTR to the Cerulean cassette was observed in both monoclonal cell lines (Figure 4B). All independent single $\mathrm{mCherry}^{+}$monoclonal cell lines contained large deletions in different regions of the vector suggesting that the plasmids were not the source of those

Peer) reviewing PDF | (2020:08:51698:1:1:NEW 13 Oct 2020) 
330 deletions. This was confirmed by next-generation sequencing of the plasmids not showing any

331 evidence for large deletions. Next, the integrated vector LTatCL[M] was sequenced in a cell

332 population of single mCherry $^{+}$cells immediately after the $1^{\text {st }}$ sort, 9 days post transfection

333 (Supplementary Figure 1). Evidence for numerous different large deletions were observed in the

334 5'HIV-1 LTR, Tat, IRES and/or Cerulean (Supplementary Figure 4), indicating that those

335 deletions occurred early during targeted integration.

\section{Discussion}

337 We developed a novel model to study HIV-1 promoter activity based on CRISPR/Cas9-mediated targeted integration of an 5'337 bp HIV-1-based, dual-fluorophore vector into selected sites in the human genome. In our previous study, we have shown that the HIV-1-based, dual-

340 fluorophore vector LTatC $[\mathrm{M}]$ reproduces features of active and latent HIV-1 infections. (Kok et al. 2018). Here, we studied the fate of the HIV-1 promoter in specific HIV-1 integration loci/sites by targeted integration of the vector LTatCL[M] into $B A C H 2$ and AAVS1. In Jurkat T-cells, $\mathrm{HIV}-1$-based vector integration into $B A C H 2$ led initially to an active HIV-1 promoter as shown by the expression of HIV-1 LTR controlled Cerulean. Over time those monoclonal cell lines showed a gradual silencing of the HIV-1 promoter. This might be due to transcriptional interference, which can occur in two ways: Either through promotor occlusion or convergent transcription, in which the transcription from the host genes interferes with HIV-1 transcription (Han et al. 2008; Lenasi et al. 2008; Shan et al. 2011). In our study, however, HIV-1 integration into the two target loci of $B A C H 2$ intron 5 and intron 2 in both orientations showed similar silencing of the HIV-1 promoter over time. Differences were observed for the safe harbour locus AAVS1, in which no substantial silencing of the HIV-1 promoter was observed over a time period of 162 days. This raises the question, whether $B A C H 2$ is an exceptional HIV-1 integration site promoting HIV-1 promoter silencing or, vice versa, AAVS1 is an exceptional HIV-1 integration site preventing HIV-1 promoter silencing. In a future study, we will be expanding the repertoire of investigated HIV-1 integration sites.

356 In virally suppressed HIV-1-infected individuals, the provirus integrated into $B A C H 2$ has been found predominantly in intron 5 in the same orientation as the gene and has been linked with clonal expansion. However, in in vitro in HIV-1 infected cell lines, integration has been found to occur randomly in the $\mathrm{BACH} 2$ gene, indicating that the integration selection observed in vivo cannot be fully recapitulated (Maldarelli et al. 2014; Wagner et al. 2014). The preference of HIV-1 integration into $B A C H 2$ intron 5 in the same orientation in vivo could be caused by: 1.) Selection of $B A C H 2$ intron 5 integrants over other integrants over time (Hughes \& Coffin 2016), 2.) $B A C H 2$ intron 5 is preferentially targeted by $\mathrm{HIV}-1$ in primary $\mathrm{CD}^{+} \mathrm{T}$-cells, presumably due to the spatial location of this locus in the nucleus of target cells (Marini et al. 2015), or 3.) distinct alterations in $B A C H 2$ expression levels caused by different HIV-1 integration patterns. $B A C H 2$ expression levels vary between T-cells in distinct differentiation stages (Richer et al. 2016). An increase of BACH 2 transcripts in regulatory and effector T-cells were observed when HIV-1 was integrated in $B A C H 2$ (Cesana et al. 2017). Enhanced expression of the wild-type $B A C H 2$ in regulatory T-cells leads to increased proliferation capacity without affecting the cells' phenotype (Cesana et al. 2017). Alteration of $B A C H 2$ expression might cause HIV-1 persistence in $B A C H 2$ intron 5 and expansion of the cell. In Jurkat T-cells, as compared to primary $\mathrm{CD}^{+} \mathrm{T}-$ cells, the $B A C H 2$ expression levels might be different (Shan et al. 2017). We measured $B A C H 2$ expression 120 days post sorting. At this time point the majority of the transfected cell clones harboured silenced HIV-1 promoters. We could not observe an inhibitory effect on $B A C H 2$ 
375

376

377

378

379

380

381

382

383

384

385

386

387

388

389

390

391

392

393

394

395

396

397

398

399

400

401

402

403

404

405

406

407

408

409

410

411

412

413

414

415

416

417

418

mRNA or protein expression when $B A C H 2$ introns 5 and 2 were targeted for integration with our HIV-1-based vector. This indicates that other factors might lead to the persistence of HIV-1 in this locus in Jurkat T-cells. HIV-1 infection into a cellular gene can affect various aspects of cellular physiology as for example proliferation or a longer half-life of the cell (Rezaei \& Cameron 2015; Wagner et al. 2014). However, there was no evidence that targeted integration of LTatCL[M] into $B A C H 2$ had an evolutionary advantage in cell growth in competition with the parental Jurkat T-cell line. The expression of Cerulean decreased over time in almost all $\mathrm{BACH} 2$ monoclonal cell clones independent of the targeted intron and the orientation of HIV-1-based vector integration. The slow decline and the presence of Cerulean positive cells for up to 162 days in some of those monoclonal cell clones shows that targeted integration of LTatCL[M] into $B A C H 2$ does not immediately and not completely lead to HIV-1 promoter silencing in Jurkat Tcells. However, insulator-protected mCherry expression also declined in some of those cell clones, suggesting a gradual and strong silencing effect at the $B A C H 2$ loci. This silencing was reversible as shown by the treatment of cell clones harbouring silenced HIV-1 promoters with TNF- $\alpha$ and Romidepsin that led to HIV-1 promoter reactivation. These observations are partly in line with Lange et al.(32): They observed a comparable reversible silencing of the HIV-1 promoter in $B A C H 2$ within 20-40 days targeting two sites within $B A C H 2$ intron 5 via CRISPR/Cas9 and inserting one reporter gene under the control of the HIV-1 LTR-promoter in the same transcriptional orientation as $B A C H 2$ (Lange et al. 2018). Here, we observed the same phenotypes in another intron of $B A C H 2$ and independent of the orientation of the HIV-1 integration. Furthermore, targeted integration of LTatCL[M] into the safe harbour site AAVS1 did not lead to silencing of the HIV-1 promoter. This model can be further expanded by insertion of, for instance, certain HIV-1 genes, which will allow to study the impact of viral genes on the host's expression profile and cell cycle.

Mono-allelic integration of $5.3 \mathrm{~kb}$ long LTatCL[M] into $B A C H 2$ and AAVS1 has been confirmed in monoclonal cell lines by amplifying and sequencing junctions of integration. So far, the longest fragment inserted in human lymphocytes was $1.5 \mathrm{~kb}$ long (Hung et al. 2018), hence, our findings show that insertion of a 3.5x larger fragment is possible in Jurkat T-cells. Fragments of similar length $(5.5 \mathrm{~kb}$ and $7.4 \mathrm{~kb})$ have been successfully integrated in other cell types (embryonic stem cells and zygotes)(Wang et al. 2015).

Monoclonal cell lines expressing initially only mCherry, i.e., supposed to model latently HIV-1 infected cells, were found to contain large deletions in the LTR-tat-Cerulean cassette. Similar deletions were already observed by us when we used a variant of our vector to generate retroviruses for infection of cells (Kok et al. 2018). There, we speculated that the deletions were caused by error-prone HIV-1 reverse transcription (Bebenek et al. 1989; Patel \& Preston 1994) or copy-choice recombination (Sanchez et al. 1997; Simon-Loriere \& Holmes 2011), which is also observed in cells from HIV-1-infected individuals (Ho et al. 2013). However, our current system does not require reverse transcriptase prior to integration since we are using CRISPR/Cas9-mediated targeted integration. Therefore, the deletions might be due to recombination events triggered by the LTRs flanking the Cerulean cassette (Mager \& Goodchild 1989). Together with our previous observation (Kok et al. 2018), our results underline the importance to further investigate single fluorescent cell populations (representing latently HIV-1 infected cells) in latency models using HIV-1-based vector systems. Beyond HIV-1, these findings might also have implications for lentiviral vectors used for gene therapy. 


\section{Conclusion}

420 Using the CRISPR/Cas9-technology, stable targeted integration of the $5.3 \mathrm{~kb}$ long HIV-1 dual-

421 fluorphore vector LTatCL[M] was successful, enabling longitudinal studies on effects of selected

422 genomic sites on HIV-1 promoter activity and cellular phenotypes. Targeting the $B A C H 2$ gene

423 revealed that loci within this gene are capable of supporting an active HIV-1 promoter upon

424 integration but its activity diminishes over time in Jurkat T-cells. On the contrary, the HIV-1

425 promoter was not silenced when integrated into the genomic safe harbour AAVSI of Jurkat T-

426 cells.

\section{Acknowledgements}

428 We are very thankful to Walter Schaffner (Institute for Molecular Life Science, UZH) for fruitful

429 discussions and critical reading of the manuscript. We thank Philipp Schätzle and Andrea

430 Henning (Flow Cytometry Facility, UZH, Zurich, Switzerland) for bulk and single cell sorting

431 services and Stefan Schmutz for technical assistance. The following reagent was obtained

432 through the NIH AIDS Reagent Program, Division of AIDS, NIAID, NIH: Sup-T1 from Dr.

433 Dharam Ablashi. This manuscript has been released as a pre-print at bioRxiv, (Inderbitzin et al.

434 2020).

435 Author contributions

436 YLK an AI designed the study, performed the experiments, analysed the data, and wrote the 437 manuscript. LJ supported the experiments and analysis of the data. KN, AK, and DH supported 438 the experiments. TC was pioneering in the design of the study. KJM invented and designed the 439 study, supported the analysis of the data, and edited the manuscript. All authors read and 440 approved the manuscript.

\section{Conflict of Interest Statement}

\section{Competing interests}

443 Karin J Metzner has received travel grants and honoraria from Gilead Sciences, Roche 444 Diagnostics, Tibotec, Bristol-Myers Squibb, and Abbott; the University of Zurich has received 445 research grants from Gilead, Roche, and Merck Sharp \& Dohme for studies that Karin J Metzner 446 serves as principal investigator, and advisory board honoraria from Gilead Sciences. The authors 447 declare that the research was conducted in the absence of any commercial or financial 448 relationships that could be construed as a potential conflict of interest. All other authors declare 449 no competing interests relevant to this study.

\section{List of Abbreviations}

451 ART: Antiretroviral therapy; BACH2: BTB domain and CNC homology 2; AAVS1: Adeno452 associated virus integration site 1; LTR: Long terminal repeat; LTatCL[M]: 5'LTR -Tat453 Cerulean-3'LTR-insulator-mCherry-insulator; TNF- $\alpha$ : Tumor Necrosis Factor Alpha;

454 Ro:Romidepsin; RIG: recurrent integration gene; 


\section{Funding disclosure}

456 This study was funded by the Swiss National Science Foundation, grant No. 310030_141067/1

457 to Karin J Metzner and from the Forschungskredit Candoc, grant No. FK-19-032 to Anne

458 Inderbitzin.

\section{Availability of Materials}

460 All constructs and cell clones are available upon request.

461 Mandatory data and required repositories

\begin{tabular}{|l|l|l|}
\hline Data-type & Required Repositories & Metadata Standard \\
\hline Genetic and genomic & GenBank & MiXS \\
sequence (DNA) & DNA Data Bank of Japan & \\
& (DDBJ) & \\
& European Nucleotide & \\
& Archive & \\
& (ENA) & \\
\hline
\end{tabular}

462 
464

465

466

467

468

469

470

471

472

473

474

475

476

477

478

479

480

481

482

483

484

485

486

487

488

489

490

491

492

493

494

495

496

497

498

499

500

501

502

503

504

505

506

507

508

\section{References}

Bebenek K, Abbotts J, Roberts JD, Wilson SH, and Kunkel TA. 1989. Specificity and mechanism of error-prone replication by human immunodeficiency virus-1 reverse transcriptase. J Biol Chem 264:16948-16956.

Cesana D, Santoni de Sio FR, Rudilosso L, Gallina P, Calabria A, Beretta S, Merelli I, Bruzzesi E, Passerini L, Nozza S, Vicenzi E, Poli G, Gregori S, Tambussi G, and Montini E. 2017. HIV-1-mediated insertional activation of STAT5B and BACH2 trigger viral reservoir in T regulatory cells. Nat Commun 8:498. 10.1038/s41467-017-00609-1

Ciuffi A, and Bushman FD. 2006. Retroviral DNA integration: HIV and the role of LEDGF/p75. Trends Genet 22:388-395. 10.1016/j.tig.2006.05.006

Cohn LB, Silva IT, Oliveira TY, Rosales RA, Parrish EH, Learn GH, Hahn BH, Czartoski JL, McElrath MJ, Lehmann C, Klein F, Caskey M, Walker BD, Siliciano JD, Siliciano RF, Jankovic M, and Nussenzweig MC. 2015. HIV-1 Integration Landscape during Latent and Active Infection. Cell 160:420-432. 10.1016/j.cell.2015.01.020

Finzi D, Hermankova M, Pierson T, Carruth LM, Buck C, Chaisson RE, Quinn TC, Chadwick K, Margolick J, Brookmeyer R, Gallant J, Markowitz M, Ho DD, Richman DD, and Siliciano RF. 1997. Identification of a reservoir for HIV-1 in patients on highly active antiretroviral therapy. Science 278:1295-1300.

Han Y, Lin YB, An W, Xu J, Yang HC, O'Connell K, Dordai D, Boeke JD, Siliciano JD, and Siliciano RF. 2008. Orientation-dependent regulation of integrated HIV-1 expression by host gene transcriptional readthrough. Cell Host Microbe 4:134-146. 10.1016/j.chom.2008.06.008

Ho YC, Shan L, Hosmane NN, Wang J, Laskey SB, Rosenbloom DI, Lai J, Blankson JN, Siliciano JD, and Siliciano RF. 2013. Replication-Competent Noninduced Proviruses in the Latent Reservoir Increase Barrier to HIV-1 Cure. Cell 155:540-551. 10.1016/j.cell.2013.09.020

S0092-8674(13)01157-4 [pii]

Hughes SH, and Coffin JM. 2016. What Integration Sites Tell Us about HIV Persistence. Cell Host Microbe 19:588-598. 10.1016/j.chom.2016.04.010

Hung KL, Meitlis I, Hale M, Chen CY, Singh S, Jackson SW, Miao CH, Khan IF, Rawlings DJ, and James RG. 2018. Engineering Protein-Secreting Plasma Cells by HomologyDirected Repair in Primary Human B Cells. Mol Ther 26:456-467. 10.1016/j.ymthe.2017.11.012

Ikeda T, Shibata J, Yoshimura K, Koito A, and Matsushita S. 2007. Recurrent HIV-1 integration at the BACH2 locus in resting CD4+ T cell populations during effective highly active antiretroviral therapy. J Infect Dis 195:716-725. 10.1086/510915

Imamichi H, Natarajan V, Adelsberger JW, Rehm CA, Lempicki RA, Das B, Hazen A, Imamichi $\mathrm{T}$, and Lane HC. 2014. Lifespan of effector memory CD4+ T cells determined by replication-incompetent integrated HIV-1 provirus. Aids 28:1091-1099. 10.1097/qad.0000000000000223

Inderbitzin A, Kok YL, Jörimann L, Kelley A, Neumann K, Heinzer D, Cathomen T, and Metzner KJ. 2020. HIV-1 promoter is gradually silenced when integrated into BACH2. bioRxiv:2020.2003.2030.011395. 10.1101/2020.03.30.011395 \%J bioRxiv

Kok YL, Schmutz S, Inderbitzin A, Neumann K, Kelley A, Jorimann L, Shilaih M, Vongrad V, Kouyos RD, Gunthard HF, Berens C, and Metzner KJ. 2018. Spontaneous reactivation 
509

510

511

512

513

514

515

516

517

518

519

520

521

522

523

524

525

526

527

528

529

530

531

532

533

534

535

536

537

538

539

540

541

542

543

544

545

546

547

548

549

550

551

552

553 of latent HIV-1 promoters is linked to the cell cycle as revealed by a geneticinsulators-containing dual-fluorescence HIV-1-based vector. Sci Rep 8:10204. 10.1038/s41598-018-28161-y

Kok YL, Vongrad V, Shilaih M, Di Giallonardo F, Kuster H, Kouyos R, Gunthard HF, and Metzner KJ. 2016. Monocyte-derived macrophages exhibit distinct and more restricted HIV-1 integration site repertoire than CD4(+) T cells. Sci Rep 6:24157. 10.1038/srep24157

Kotin RM, Linden RM, and Berns KI. 1992. Characterization of a preferred site on human chromosome $19 \mathrm{q}$ for integration of adeno-associated virus DNA by non-homologous recombination. Embo j 11:5071-5078.

Lange UC, Bialek JK, Walther T, and Hauber J. 2018. Pinpointing recurrent proviral integration sites in new models for latent HIV-1 infection. Virus Res 249:69-75. 10.1016/j.virusres.2018.03.007

Lenasi T, Contreras X, and Peterlin BM. 2008. Transcriptional interference antagonizes proviral gene expression to promote HIV latency. Cell Host Microbe 4:123-133. 10.1016/j.chom.2008.05.016

Livak KJ, and Schmittgen TD. 2001. Analysis of relative gene expression data using realtime quantitative PCR and the 2(-Delta Delta C(T)) Method. Methods 25:402-408. 10.1006/meth.2001.1262

Mack KD, Jin X, Yu S, Wei R, Kapp L, Green C, Herndier B, Abbey NW, Elbaggari A, Liu Y, and McGrath MS. 2003. HIV insertions within and proximal to host cell genes are a common finding in tissues containing high levels of HIV DNA and macrophageassociated p24 antigen expression. J Acquir Immune Defic Syndr 33:308-320.

Mager DL, and Goodchild NL. 1989. Homologous recombination between the LTRs of a human retrovirus-like element causes a 5 -kb deletion in two siblings. Am J Hum Genet 45:848-854.

Maldarelli F, Wu X, Su L, Simonetti FR, Shao W, Hill S, Spindler J, Ferris AL, Mellors JW, Kearney MF, Coffin JM, and Hughes SH. 2014. HIV latency. Specific HIV integration sites are linked to clonal expansion and persistence of infected cells. Science 345:179-183. 10.1126/science.1254194

Marini B, Kertesz-Farkas A, Ali H, Lucic B, Lisek K, Manganaro L, Pongor S, Luzzati R, Recchia A, Mavilio F, Giacca M, and Lusic M. 2015. Nuclear architecture dictates HIV1 integration site selection. Nature 521:227-231. 10.1038/nature14226

Mitchell RS, Beitzel BF, Schroder AR, Shinn P, Chen H, Berry CC, Ecker JR, and Bushman FD. 2004. Retroviral DNA integration: ASLV, HIV, and MLV show distinct target site preferences. PLoS Biol 2:E234. 10.1371/journal.pbio.0020234

Papapetrou EP, and Schambach A. 2016. Gene Insertion Into Genomic Safe Harbors for Human Gene Therapy. Mol Ther 24:678-684. 10.1038/mt.2016.38

Patel PH, and Preston BD. 1994. Marked infidelity of human immunodeficiency virus type 1 reverse transcriptase at RNA and DNA template ends. Proc Natl Acad Sci USA 91:549-553.

Ran FA, Hsu PD, Wright J, Agarwala V, Scott DA, and Zhang F. 2013. Genome engineering using the CRISPR-Cas9 system. Nat Protoc 8:2281-2308. 10.1038/nprot.2013.143

Rezaei SD, and Cameron PU. 2015. Human immunodeficiency virus (HIV)-1 integration sites in viral latency. Curr HIV/AIDS Rep 12:88-96. 10.1007/s11904-014-0241-9 
554 Richer MJ, Lang ML, and Butler NS. 2016. T Cell Fates Zipped Up: How the Bach2 Basic 555 Leucine Zipper Transcriptional Repressor Directs $\mathrm{T}$ Cell Differentiation and 556

Ruelas DS, and Greene WC. 2013. An integrated overview of HIV-1 latency. Cell 155:519529. 10.1016/j.cell.2013.09.044

Sadelain M, Papapetrou EP, and Bushman FD. 2011. Safe harbours for the integration of new DNA in the human genome. Nat Rev Cancer 12:51-58. 10.1038/nrc3179

Sanchez G, Xu X, Chermann JC, and Hirsch I. 1997. Accumulation of defective viral genomes in peripheral blood mononuclear cells of human immunodeficiency virus type 1infected individuals. J Virol 71:2233-2240.

Satou Y, Katsuya H, Fukuda A, Misawa N, Ito J, Uchiyama Y, Miyazato P, Islam S, Fassati A, Melamed A, Bangham CRM, Koyanagi Y, and Sato K. 2017. Dynamics and mechanisms of clonal expansion of HIV-1-infected cells in a humanized mouse model. Sci Rep 7:6913. 10.1038/s41598-017-07307-4

Schroder AR, Shinn P, Chen H, Berry C, Ecker JR, and Bushman F. 2002. HIV-1 integration in the human genome favors active genes and local hotspots. Cell 110:521-529.

Shan L, Deng K, Gao H, Xing S, Capoferri AA, Durand CM, Rabi SA, Laird GM, Kim M, Hosmane NN, Yang HC, Zhang H, Margolick JB, Li L, Cai W, Ke R, Flavell RA, Siliciano JD, and Siliciano RF. 2017. Transcriptional Reprogramming during Effector-toMemory Transition Renders CD4(+) T Cells Permissive for Latent HIV-1 Infection. Immunity 47:766-775.e763. 10.1016/j.immuni.2017.09.014

Shan L, Yang HC, Rabi SA, Bravo HC, Shroff NS, Irizarry RA, Zhang H, Margolick JB, Siliciano JD, and Siliciano RF. 2011. Influence of host gene transcription level and orientation on HIV-1 latency in a primary-cell model. J Virol 85:5384-5393. 10.1128/jvi.0253610

Simon-Loriere E, and Holmes EC. 2011. Why do RNA viruses recombine? Nat Rev Microbiol 9:617-626. 10.1038/nrmicro2614

Sogaard OS, Graversen ME, Leth S, Olesen R, Brinkmann CR, Nissen SK, Kjaer AS, Schleimann MH, Denton PW, Hey-Cunningham WJ, Koelsch KK, Pantaleo G, Krogsgaard K, Sommerfelt M, Fromentin R, Chomont N, Rasmussen TA, Ostergaard L, and Tolstrup M. 2015. The Depsipeptide Romidepsin Reverses HIV-1 Latency In Vivo. PLoS Pathog 11:e1005142. 10.1371/journal.ppat.1005142

Stevens SW, and Griffith JD. 1996. Sequence analysis of the human DNA flanking sites of human immunodeficiency virus type 1 integration. J Virol 70:6459-6462.

Uchida N, Hanawa H, Yamamoto M, and Shimada T. 2013. The chicken hypersensitivity site 4 core insulator blocks promoter interference in lentiviral vectors. Hum Gene Ther Methods 24:117-124. 10.1089/hgtb.2012.152

Villemure JF, Savard N, and Belmaaza A. 2001. Promoter suppression in cultured mammalian cells can be blocked by the chicken beta-globin chromatin insulator 5'HS4 and matrix/scaffold attachment regions. J Mol Biol 312:963-974. 10.1006/jmbi.2001.5015

Wagner TA, McLaughlin S, Garg K, Cheung CY, Larsen BB, Styrchak S, Huang HC, Edlefsen PT, Mullins JI, and Frenkel LM. 2014. HIV latency. Proliferation of cells with HIV integrated into cancer genes contributes to persistent infection. Science 345:570573. $10.1126 /$ science. 1256304

Peer) reviewing PDF | (2020:08:51698:1:1:NEW 13 Oct 2020) 
599 Wang B, Li K, Wang A, Reiser M, Saunders T, Lockey RF, and Wang JW. 2015. Highly 600 efficient CRISPR/HDR-mediated knock-in for mouse embryonic stem cells and 601

602 zygotes. Biotechniques 59:201-202, 204, 206-208. 10.2144/000114339

Wong JK, Hezareh M, Gunthard HF, Havlir DV, Ignacio CC, Spina CA, and Richman DD. 1997. Recovery of replication-competent HIV despite prolonged suppression of plasma viremia. Science 278:1291-1295.

604

605

Yahata K, Maeshima K, Sone T, Ando T, Okabe M, Imamoto N, and Imamoto F. 2007. cHS4 insulator-mediated alleviation of promoter interference during cell-based expression of tandemly associated transgenes. J Mol Biol 374:580-590.

607

608 10.1016/j.jmb.2007.09.054

609

610 


\section{Figure 1}

Targeted integration of the dual-fluorophore vector LTatCL[M] into specific genomic loci in Jurkat T-cells.

(A) Schematic diagram of the six HIV-1 based, dual-fluorophore vectors LTatCL[M] (5'337 bp) flanked with the BACH2/AAVS1 homologous arms. LTatCL[M] contains two fluorophores (Cerulean and mCherry) to distinguish between inactive and active HIV-1 promoters, i.e., modelling latently and actively HIV-1 infected cells. The Cerulean cassette is under the control of the HIV-1 LTR whereas mCherry is under the control of an independent constitutive promoter (helF4A1) and flanked by two insulators (CHS4 and SMAR8). LTR, long terminal repeat; tat, HIV-1 transactivator; IRES, internal ribosome entry site; CHS4, chicken hypersensitive site 4; tetO, tetracycline operator sequences; helF4A1, human eukaryotic initiation factor 4A1, gene promoter; SMAR8, synthetic matrix attachment region 8. (B) Scheme of the targeted HIV-1 integration sites in BACH2 and AAVS1. Some described HIV-1 integration sites in vivo are marked by red arrows (Maldarelli, et al. 2014, Wagner, et al.

2014) . (C) Percentage of Cerulean ${ }^{+} / \mathrm{mCherry}^{+}$(white bars) and single $\mathrm{mCherry}^{+}$(black bars) cells 9 days post transduction of Jurkat T-cells targeting the different loci in $\mathrm{BACH} 2$ and AAVS1. The means and standard deviations of 3 independent experiments are depicted. (D) Flow chart to generate monoclonal cell lines. Jurkat T-cells were separately transfected with the vectors shown in A and the corresponding gRNA/Cas9 plasmid. Nine days post transfection, the six different targeted HIV-1 integration variants were each sorted by 20 cells per well for the phenotypes Cerulean ${ }^{+} / \mathrm{mCherry}^{+}$and single $\mathrm{mCherry}^{+}$. Fifty days post transfection, the cells were single cell sorted for each targeted integration variant for the two phenotypes Cerulean ${ }^{+} / \mathrm{mCherry}^{+}$and single $m$ Cherry $^{+}$. After at least 25 days post $2^{\text {nd }}$ sorting, cells were further characterized. (A-D). The in vivo observed preferential HIV-1 integration 
loci in $B A C H 2, B A C H 2$ i5s, is highlighted by red boxes. 
A

dual-fluorophore LTR-Tat/Cerulean-LTR-ins-helF4A1/mCherry-ins (LTatCL[M]) vector cassette

AACH2_i5s

B

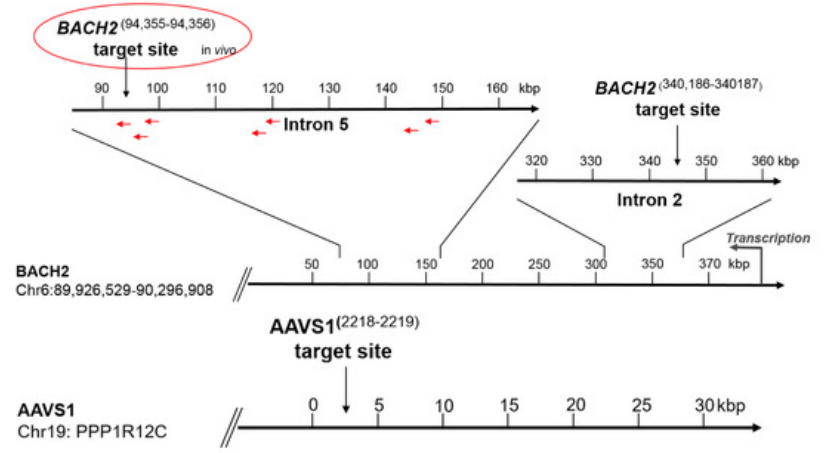

C

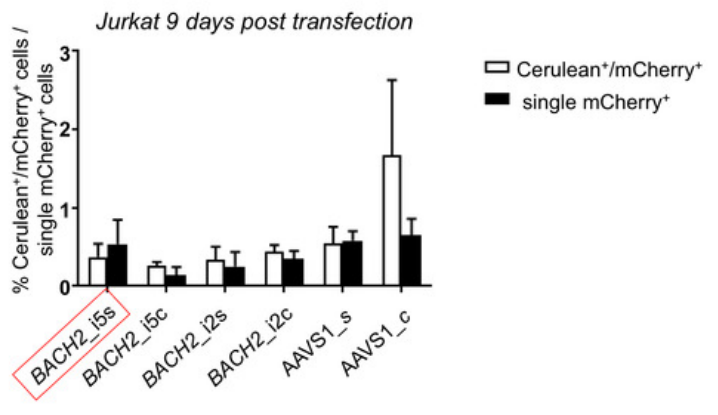

D
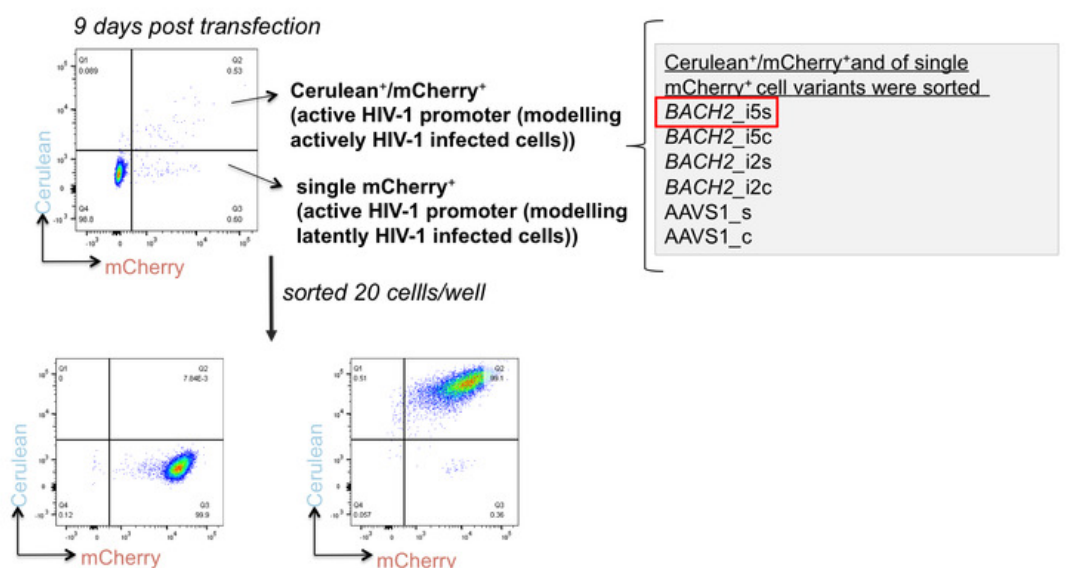

sorted single cellls/well 50 days post transfection single mCherry ${ }^{+}$

(inactive HIV-1 promoter)

Cerulean $/ \mathrm{mCherry}^{+}$

$\geq 25$ days post $2^{\text {nd }}$ sort

(active HIV-1 promoter)

Characterization of of single cell clone

- verify integration via PCR/sequencing

- mono-or bi-allelic integration

- BACH2 protein expression

- Iongitudinal FACS analyses of fluorophores expression

- promoter activation assay 


\section{Figure 2}

The mono-allelic integration of $L T a t C L[M]$ into $B A C H 2$ did not impair $B A C H 2$ mRNA nor $\mathrm{BACH} 2$ protein expression measured 120 days post sorting.

(A) BACH2 mRNA expression was quantified by amplification of a region in the mRNA downstream of $\mathrm{BACH}_{2} \mathrm{i} 5$ and $\mathrm{BACH}_{2} \mathrm{i} 2$. The bar blot consists of two independent $\mathrm{qPCR}$ experiments, consisting of two replicates each. The qPCR was carried out two times independently in duplicate. The means and standard deviations are depicted. One-way ANOVA was performed on all cell clone variants and showed no significance $(p=0.80)$.

(B)Western blot analysis of BACH2 protein expression, $110 \mathrm{kD} \mathrm{BACH2} \mathrm{(upper} \mathrm{panel)} \mathrm{and} 37$ kD GAPDH (lower panel) are shown for an exemplary experiment. The in vivo observed preferential HIV-1 integration loci in $\mathrm{BACH} 2, \mathrm{BACH} 2$ i $5 \mathrm{~s}$, is highlighted by red boxes.

A

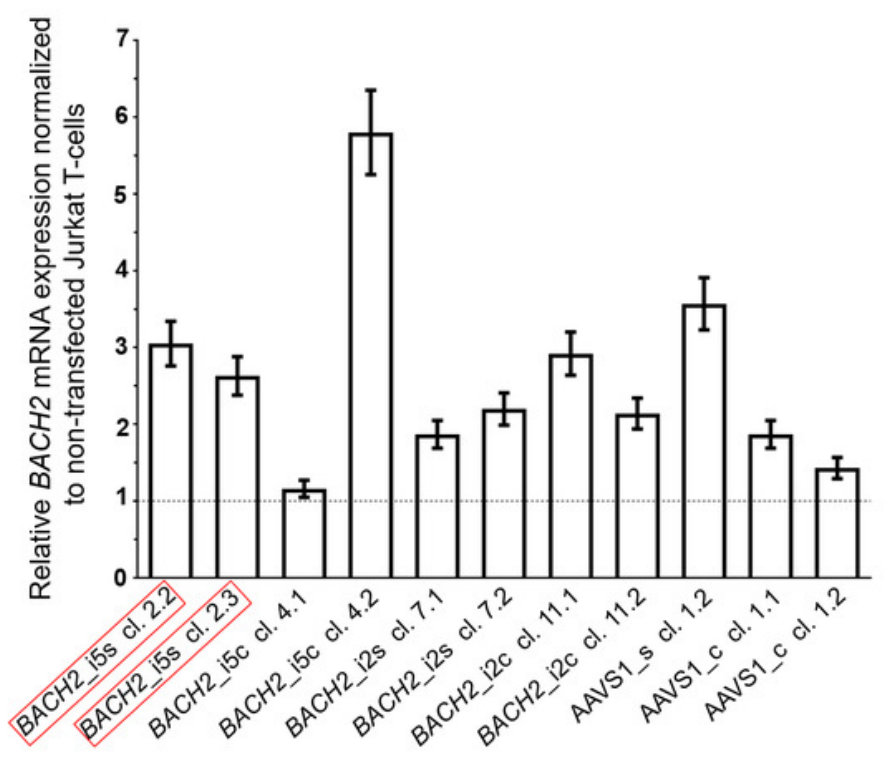

B

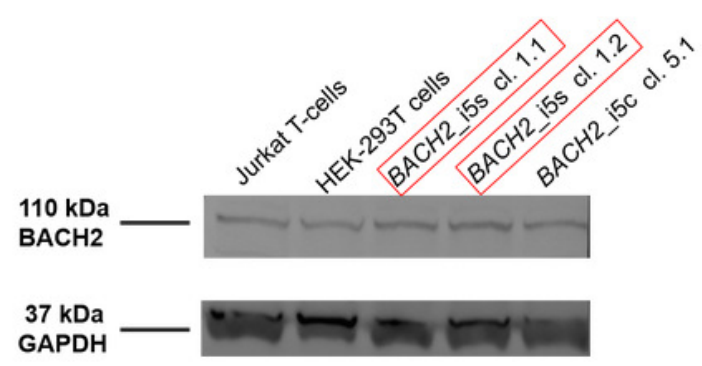




\section{Figure 3}

Longitudinal analysis of Cerulean ${ }^{+} / \mathrm{mCherry}^{+}$monoclonal cell lines and reactivation of silenced HIV-1 promoter.

(A) Longitudinal frequency of Cerulean ${ }^{+} / \mathrm{mCherry}^{+}$expression in 24 monoclonal cell lines for up to 162 days: $3 \times \mathrm{BACH}_{-} \mathrm{i} 5 \mathrm{~s}$ (depicted in red, first left panel), $4 \times \mathrm{BACH} 2 \mathrm{i} 5 \mathrm{c}, 7 \times \mathrm{BACH} 2 \mathrm{i} 2 \mathrm{~s}$, 4x BACH2_i2c, 3x AAVS1_s, and 3x AAVS1_c. Each symbol represents one Cerulean ${ }^{+} / \mathrm{mCherry}^{+}$monoclonal cell line. (B) Reactivation of silenced HIV-1 promoter upon treatment of monoclonal cell lines with $10 \mathrm{ng} / \mu \mathrm{L}$ TNF- $\alpha$ and $4 \mathrm{nM}$ Romidepsin for 24 hours followed by FACS analysis. The experiment was carried out three times independently. The in vivo observed HIV-1 integration loci in $B A C H 2, B A C H 2$ _i5s, is highlighted by red boxes. 
A

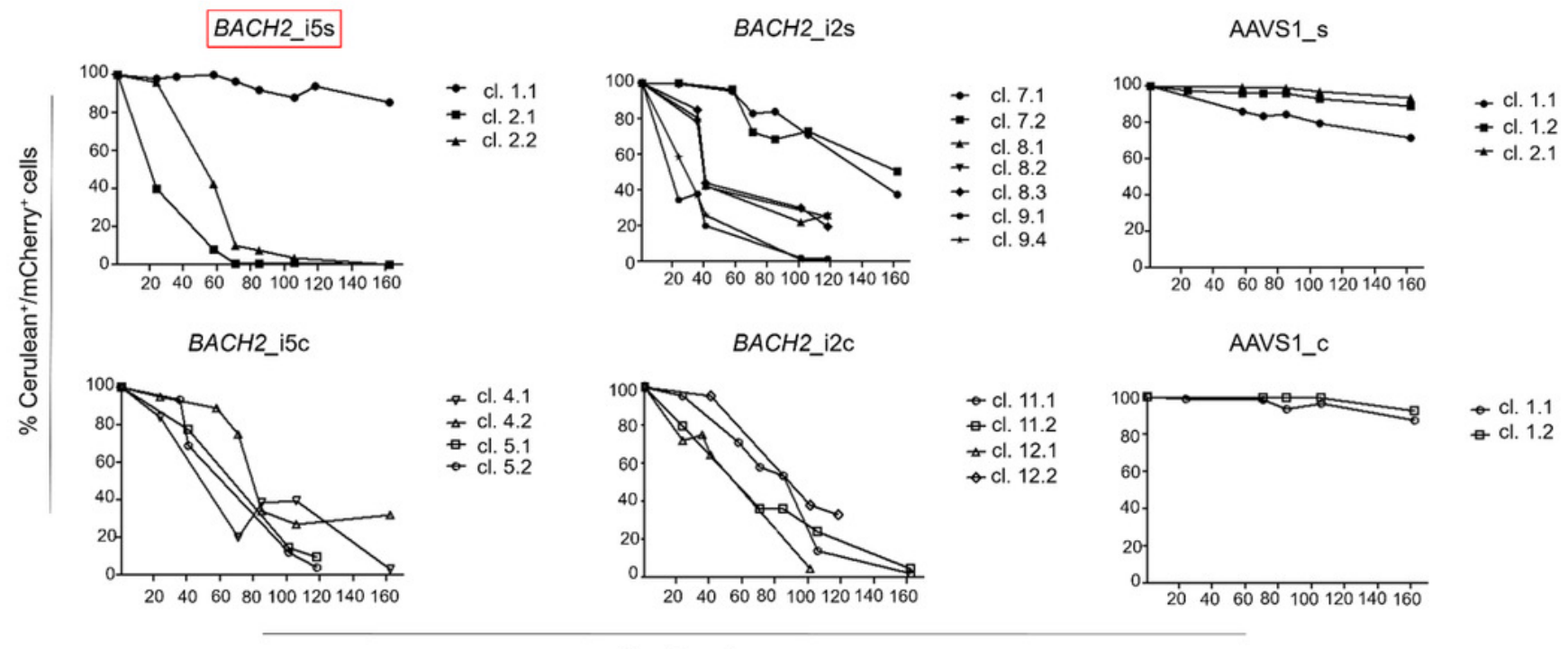

B

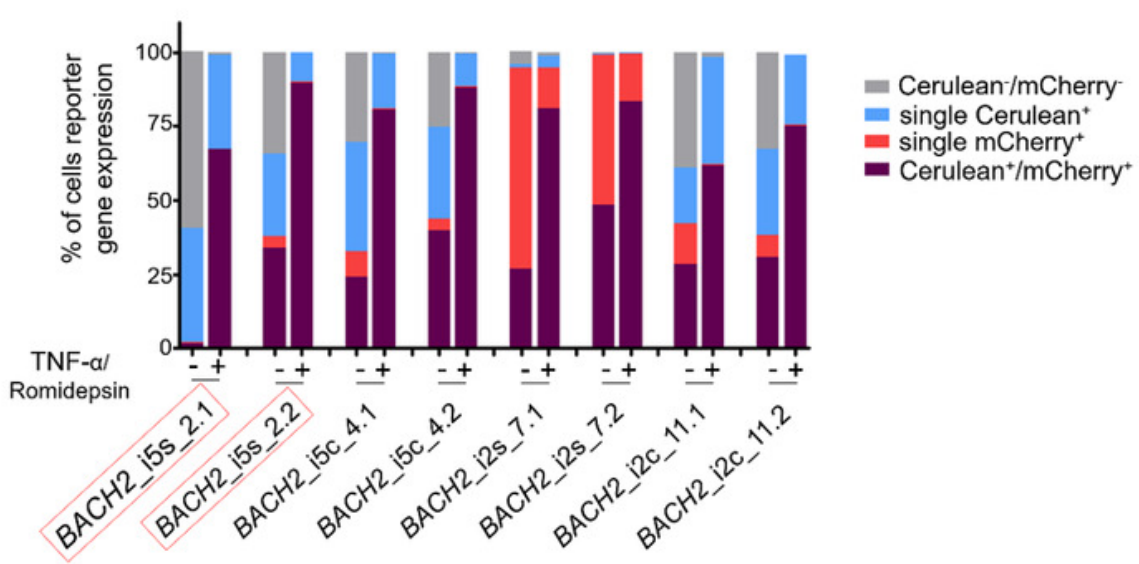




\section{Figure 4}

Mapping of large deletions within LTatCL[M] in TNF- $\alpha /$ Romidepsin non-responsive, single mCherry ${ }^{+}$monoclonal cell lines.

Deletions in the integrated vector $\mathrm{LTatCL}[\mathrm{M}]$ are depicted for monoclonal $B A C H 2 \_\mathrm{i} 5$, $B A C H 2$ i2, and AAVS1 monoclonal cell lines with integrated LTatCL[M] in the same transcriptional orientation (A) and in the convergent transcriptional orientation (B). Black horizontal bars show the amplified and sequenced regions of LTatCL[M] and large deletions are shown in white horizontal bars. Light blue and light red vertical bars show the positions of the two fluorophores Cerulean and mCherry, respectively. Vector schemes are depicted on top. The in vivo observed HIV-1 integration region site in $B A C H 2, B A C H 2$ i i5s, is highlighted by red boxes. Different starting points of amplicons were due to using different primer pairs for amplifications. 
A

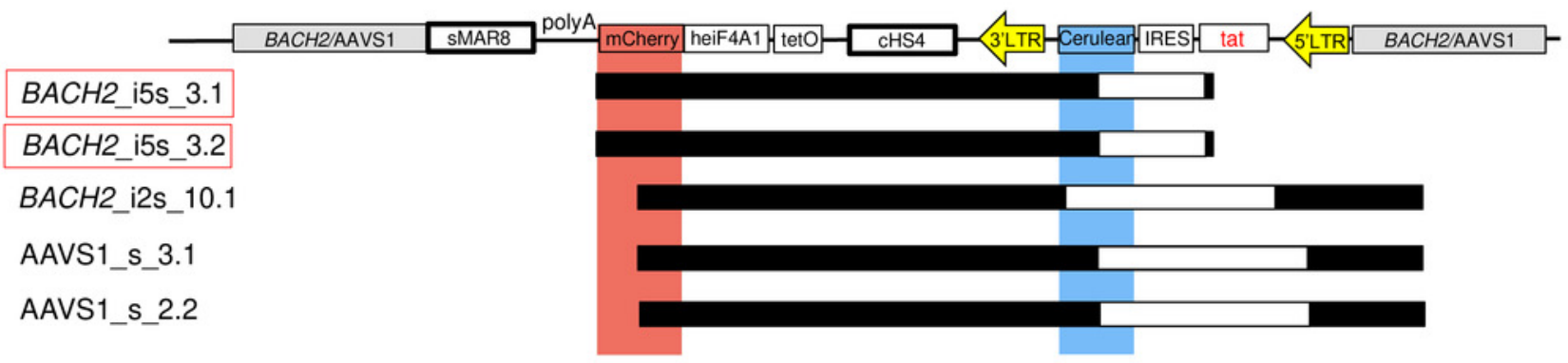

B

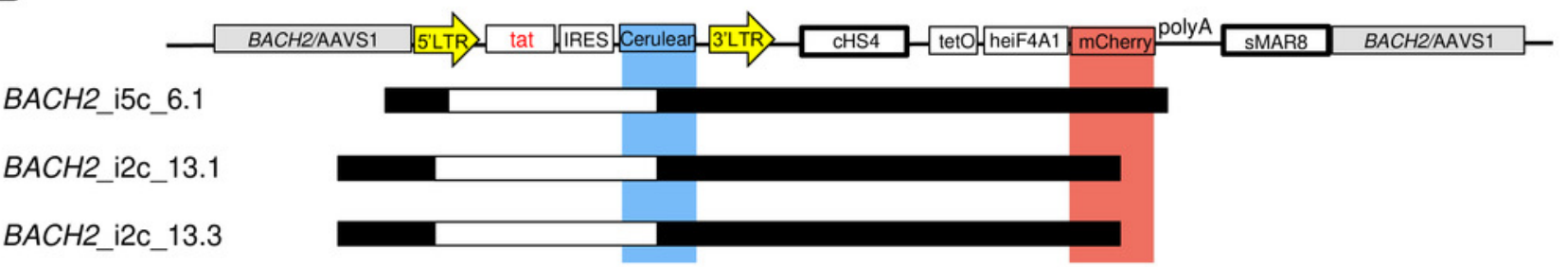




\section{Table $\mathbf{1}$ (on next page)}

Characteristics of monoclonal Jurkat T-cell lines after targeted integration of LTatCL[M] into BACH2 and AAVS1.

Cerulean ${ }^{+} / \mathrm{mCherry}^{+}$and single $\mathrm{mCherry}^{+}$representing active and inactive HIV-1 promoters in LTatCL[M] transfected cells. The in vivo observed preferential HIV-1 integration loci in BACH2, $\mathrm{BACH}_{2}$ i5s, is highlighted by a red box. 


\begin{tabular}{|c|c|c|c|c|c|c|}
\hline $\begin{array}{c}\text { LTatCL[M] } \\
\text { integration site and } \\
\text { orientation }\end{array}$ & $\begin{array}{l}\text { HIV-1 promoter } \\
\text { phenotype }^{1}\end{array}$ & $\begin{array}{l}\text { monoclonal cell } \\
\text { lines (n) }\end{array}$ & $\begin{array}{l}\text { targeted integration } \\
\text { confirmed by PCR }\end{array}$ & $\begin{array}{c}\text { mono-allelic } \\
\text { targeted } \\
\text { integration }\end{array}$ & $\begin{array}{l}\text { unaltered } B A C H 2 \\
\text { mRNA expression }\end{array}$ & $\begin{array}{l}\text { unaltered } \mathrm{BACH} 2 \\
\text { protein expression }\end{array}$ \\
\hline \multirow{2}{*}{ BACH2_i5s } & active & 6 & $5 / 6(83.3 \%)$ & $5 / 5(100 \%)$ & $2 / 2(100 \%)$ & $5 / 5(100 \%)$ \\
\hline & inactive & 7 & $5 / 7(71.4 \%)$ & $5 / 5(100 \%)$ & n.a. & $4 / 4(100 \%)$ \\
\hline \multirow{2}{*}{$B A C H 2 \_\mathrm{i} 5 \mathrm{c}$} & active & 4 & $4 / 4(100 \%)$ & $4 / 4(100 \%)$ & $2 / 2(100 \%)$ & $4 / 4(100 \%)$ \\
\hline & inactive & 1 & $1 / 1(100 \%)$ & $1 / 1(100 \%)$ & n.a. & $1 / 1(100 \%)$ \\
\hline \multirow{2}{*}{ BACH2_i2s } & active & 7 & $7 / 7(100 \%)$ & $7 / 7(100 \%)$ & $2 / 2(100 \%)$ & 7/7 (100\%) \\
\hline & inactive & 4 & $3 / 4(75 \%)$ & $3 / 3(100 \%)$ & n.a. & $3 / 3(100 \%)$ \\
\hline \multirow{2}{*}{ BACH2_i2c } & active & 4 & $4 / 4(100 \%)$ & $4 / 4(100 \%)$ & $2 / 2(100 \%)$ & $4 / 4(100 \%)$ \\
\hline & inactive & 2 & $2 / 2(100 \%)$ & $2 / 2(100 \%)$ & n.a. & $2 / 2(100 \%)$ \\
\hline \multirow{2}{*}{ AAVS1_s } & active & 2 & $2 / 2(100 \%)$ & $2 / 2(100 \%)$ & $1 / 1(100 \%)$ & $2 / 2(100 \%)$ \\
\hline & inactive & 3 & $3 / 3(100 \%)$ & $3 / 3(100 \%)$ & n.a. & n.a. \\
\hline \multirow{2}{*}{ AAVS1_c } & active & 3 & $3 / 3(100 \%)$ & $3 / 3(100 \%)$ & $2 / 2(100 \%)$ & $3 / 3(100 \%)$ \\
\hline & inactive & n.a. & n.a. & n.a. & n.a. & n.a. \\
\hline Total & & 43 & $39 / 43(90.7 \%)$ & $39 / 39(100 \%)$ & $11 / 11(100 \%)$ & $35 / 35(100 \%)$ \\
\hline
\end{tabular}

